\title{
VALORAÇÃO DO RECURSO "ÁGUA" A PARTIR DA DISPOSIÇÃO A PAGAR DOS USUÁRIOS: ESTUDO APLICADO NAS ÁREAS ATENDIDAS PELA COSANPA NA REGIÃO METROPOLITANA DE BELÉM
}

\author{
VALUATION OF “WATER” RESOURCE FROM THE \\ WILLINGNESS TO PAY BY USERS: STUDY APPLIED IN \\ AREAS COVERED BY COSANPA IN THE \\ METROPOLITAN AREA OF BELEM
}

\section{Verena Gonzaga Borges Novaes ${ }^{1}$; Ismael Matos da Silva ${ }^{1}$}

\author{
${ }^{1}$ Universidade do Estado do Pará - E-mail: borgesverena@gmail.com
}

\begin{abstract}
RESUMO
Apesar de possuir água em abundância, a região amazônica sofre com a falta de qualidade do recurso hídrico. Dentre as causas desse problema, destaca-se o lançamento indevido de esgoto in natura nos rios amazônicos. Na Região Metropolitana de Belém (RMB), do total de esgoto residencial produzido, menos de $2 \%$ são tratados. Além da falta de tratamento, há também o desperdício, que se relaciona diretamente com a quantidade de efluente produzido. Atualmente, o preço mínimo cobrado pela companhia de saneamento e abastecimento de água (COSANPA) por $\mathrm{m}^{3}$ de água é de $\mathrm{R} \$ 1,40$, valor que envolve somente os custos de distribuição e tratamento da água, desconsiderando-a como bem econômico. Com vistas a essa situação, o presente trabalho propõe uma metodologia para estipular a cobrança do valor econômico da água e propiciar fundos para a reestruturação do sistema de abastecimento de água, bem como a expansão do sistema de coleta de esgoto da COSANPA. A pesquisa adota como objeto de estudo as áreas residenciais da RMB que são abastecidas pela COSANPA. A metodologia escolhida é o Método de Valoração Contingente, a partir da Disposição a Pagar (DAP) da população amostrada. A análise dos dados realiza-se por regressão linear, pelo método dos Mínimos Quadrados Ordinários. A DAP média estimada foi de $\mathrm{R} \$ 2,22$, resultando na arrecadação anual de cerca de $\mathrm{R} \$ 40$ milhões, que poderão ser usados para efetivar melhorias técnicas no sistema de abastecimento e proporcionar a expansão do sistema de coleta e tratamento de efluentes.
\end{abstract}

Palavras-chave: Método de Valoração Contingente. Disposição a Pagar. Mínimos Quadrados Ordinários.

\footnotetext{
ABSTRACT

In spite of having plenty of water, the Amazon region suffers from a lack of quality of the water resource. Among the causes of this problem, stands out improper release of raw sewage in Amazonian rivers. In the Metropolitan Region of Belém (RMB) of the total residential sewage produced, less than $2 \%$ is treated. Besides the lack of treatment, there is also wastage, which relates directly to the quantity of effluent produced. Currently, the minimum price charged by the sanitation and water supply company (COSANPA) per $m 3$ of water is $R \$ 1,40$, value that includes
} 
only the costs of distribution and water treatment, not considering it as an economic good. Towards this situation, this work proposes a methodology to stipulate the recovery of the economic value of water and to provide funds for the restructuring of the water supply system, as well as the expansion of the wastewater collection system of COSANPA. The research adopts as object the study of the residential areas of the RMB supplied by COSANPA. The chosen methodology is the Contingent Valuation Method, from the Willingness to Pay (WP) of the sampled population. Data analysis is performed through linear regression, by the method of Ordinary Least Squares. The estimated Willingness to Pay average was $\mathrm{R} \$ 2,22$, resulting in annual revenues of approximately $\mathrm{R} \$ 40$ million, which could be used to carry out technical improvements in the supply system and provide the expansion of the collection system and the treatment of the effluents.

Keywords: Method of Contingent Valuation. Willingness to Pay. Ordinary Least Squares.

\section{INTRODUÇÃO}

A água é um recurso natural essencial para a sobrevivência de todo ser vivo e possui múltiplas utilizações nas diversas atividades humanas, sendo indispensável para o desenvolvimento econômico e para o bem-estar da sociedade. Apesar de estar em constante renovação, através do ciclo hidrológico, a água caracteriza-se como um bem natural escasso, resultando na falta do recurso em muitas regiões do planeta.

De acordo com dados da Agência Nacional de Águas (ANA) (2005 apud Couceiro, Hamada 2011), o Brasil detém aproximadamente $12 \%$ das águas superficiais do planeta, dos quais $74 \%$ estão localizadas na Amazônia. Nesse contexto, tem-se a ilusão de que a região amazônica possui reserva hídrica imensurável, não sendo necessário o fomento da discussão sobre o gerenciamento da água, nem mesmo a implantação da cobrança pelo uso do recurso.

Apesar da abundância no âmbito quantitativo, a região amazônica sofre com outro problema: a qualidade do recurso hídrico. Hartmann (2010) destaca que as causas deste problema podem ser encontradas, dentre outras, no lançamento de efluentes industriais e domésticos, através das companhias de saneamento municipais. O esgoto produzido é descartado in natura diretamente nos rios comprometendo a reserva hídrica da região devido à elevada carga de contaminação.

Na Região Metropolitana de Belém (RMB), foco do estudo deste trabalho, apenas $15 \%$ da população conta com sistemas públicos de esgotamento sanitário, sendo que $12 \%$ referem-se à cidade de Belém e 3\% à Ananindeua. Portanto, os outros municípios da RMB encontram-se desprovidos de sistema de coleta e tratamento de efluentes (Pereira et al., 2006). No entanto, não ocorre tratamento do total de esgoto coletado. Levando em consideração dados do SNIS (2012), afirma-se que do total de efluente gerado na Região Metropolitana de Belém (RMB), apenas 1,73\% é verdadeiramente coletado e passa por um processo de tratamento antes de ser despejado no corpo hídrico receptor.

Além disso, parte do efluente lançado nos rios é consequência direta do desperdício, uma vez que que não há nenhum instrumento econômico implantado, a fim de regular a vazão da água consumida pela população e incentivar a racionalização desse recurso. Portanto, a cobrança pelo uso da água faz-se fundamental, a fim de reconhecê-la como bem econômico (dotado de valor real) e diminuir as elevadas taxas de desperdício hoje existentes.

Atualmente, o valor mínimo cobrado pela companhia responsável pelo tratamento e distribuição da água na RMB é de $\mathrm{R} \$ 1,40$ e envolve os custos de tratamento e distribuição da água, desconsiderando seu valor econômico. Por isso, enseja-se determinar o valor real da água no cálculo do consumo, a partir do Método de Valoração Contingente (MVC). Assim, futuramente, poderá funcionar como auxílio à efetivação da cobrança pelo uso de recursos hídricos na RMB. 


\section{MATERIAL E MÉTODOS}

Dentro da RMB, a Companhia de Saneamento do Pará (COSANPA, 2014a) é quem gerencia o sistema de abastecimento de água na maior parte dos municípios da Região. Dentre eles, destacam-se os municípios de Belém, Ananindeua e Marituba, cujas áreas atendidas pela COSANPA (2014b) constituem a área deste estudo.

A concessionária divide sua área de atendimento em unidades de negócios (UN), a fim de facilitar a gestão financeira em cada região. Destaca-se que a as unidades UN-Norte e UN-Sul dizem respeito a áreas localizadas na cidade de Belém. A UN-AM faz referência aos bairros próximos à Avenida Augusto Montenegro, também situados em Belém, e a UN-BR aos bairros que se localizam ao longo da BR 316, englobando os municípios de Ananindeua e Marituba. A divisão entre unidades pode ser observada na figura 1.

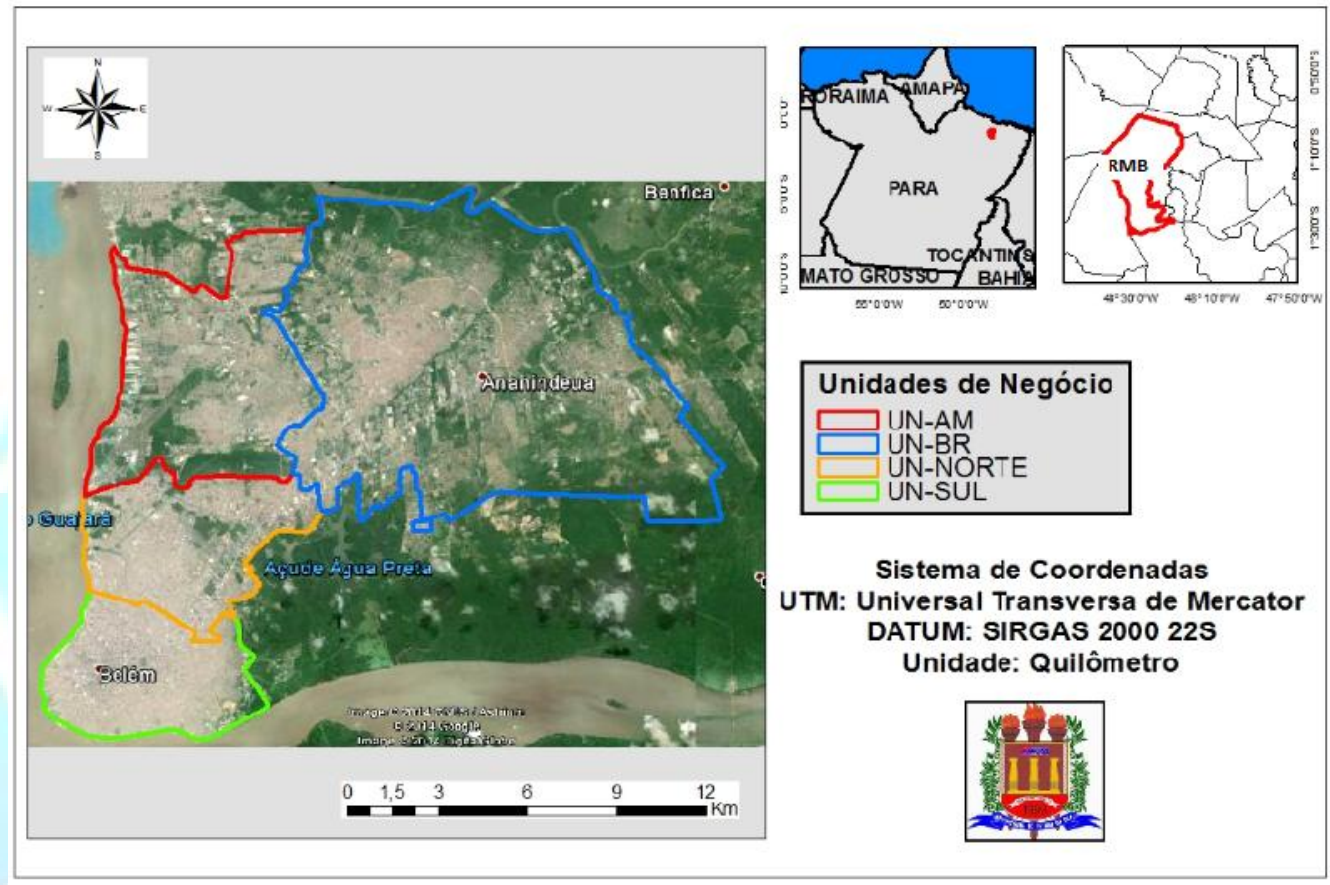

Figura 1. Unidades de Negócio da COSANPA na RMB (2014a)

A partir do número de economias existentes em cada unidade, disponibilizado pela COSANPA, foi possível calcular o espaço amostral correspondente para cada área. A população amostral foi calculada a partir da fórmula utilizada por Silva (2001):

$$
n=\frac{Z^{2} \cdot p \cdot q \cdot N}{e^{2} \cdot(N-1)+Z^{2} \cdot p \cdot q}
$$

Onde: $\mathrm{n}=$ Tamanho da amostra que se deseja encontrar; $\mathrm{N}=$ Número total de economias ligadas à rede de abastecimento público na RMB; $\mathrm{p}, \mathrm{q}=$ Probabilidades adotadas no estudo (como não há uma proporção determinada entre $\mathrm{p}$ e $\mathrm{q}$, adota-se o valor de 0,5 para ambos, como recomendado por Silva, 2001); $Z$ = Nível de confiança adotado, indicando a porcentagem que os dados obtidos sejam válidos para a população total. Considera-se $\mathrm{Z}=1,96$ (grau de confiança de 95\%); e = Erro máximo utilizado, estipulado em 5\%.

A tabela 1 mostra o resultado do cálculo de amostragem, totalizando 386 questionários a serem aplicados em vários pontos da RMB, a fim de garantir a relevância estatística do trabalho. 
Tabela 1. Cálculo do espaço amostral

\begin{tabular}{ccc}
\hline Unidades & $\begin{array}{c}\text { Número de } \\
\text { economias }\end{array}$ & $\begin{array}{c}\text { Espaço } \\
\text { amostral }\end{array}$ \\
\hline UN-AM & 37.873 & 50 \\
UN-BR & 48.960 & 64 \\
UN-Norte & 90.056 & 118 \\
UN-Sul & 117.973 & 154 \\
Total & 294.862 & 386 \\
\hline
\end{tabular}

A metodologia abordada para valorar o recurso "água" foi o MVC. Segundo Motta (2006, p.21), "o MVC procura mensurar monetariamente o impacto no nível de bem-estar dos indivíduos decorrentes de uma variável quantitativa ou qualitativa dos bens ambientais." Esse método é utilizado para estimar o valor de bens públicos que não possuem mercado (como é o caso da água), ou seja, não há como comparar suas oscilações de preço baseadas no mercado do produto final ou de bens substitutos ou complementares.

O MVC extrai dos próprios agentes econômicos, mediante pesquisas diretas com os consumidores, o valor que os mesmos estão dispostos a pagar por bens públicos. Desse modo, é criado e apresentado ao consumidor um mercado hipotético para o bem em questão, dando a oportunidade de que o usuário opte ou não por ele. Empregando- esse método, é possível revelar a valoração de bens públicos (Carrera-Fernandez e Menezes, 2000).

O valor de $\mathrm{R} \$ 1,40$ é o preço mínimo do $\mathrm{m}^{3}$ cobrado pela COSANPA. Neste valor, não está incluso o valor econômico do recurso, abrangendo apenas os custos de tratamento e distribuição da água. A COSANPA adota preços diferenciados, quanto maior o consumo, maior é o preço do $\mathrm{m}^{3} \mathrm{da}$ água.

O ponto inicial escolhido para a aplicação do MVC foi o preço mínimo do $\mathrm{m}^{3}$. A partir desse valor, indagou-se sobre a Disposição a Pagar (DAP) dos entrevistados por água de melhor qualidade, além do valor mínimo pago atualmente. De tal modo que o excedente obtido seja revertido em investimentos no sistema de abastecimento de água, bem como possibilitar a expansão da coleta e do tratamento de efluentes na RMB.

Após a aplicação dos questionários, em pontos de alta circulação da RMB, foi realizada a caracterização dos dados obtidos, de forma a estruturar o perfil do consumidor de água da COSANPA na RMB. Fez-se também a análise das DAP apresentadas pelos entrevistados durante o estudo, mediante a técnica de Mínimos Quadrados Ordinários (MQO), indicativo da regressão linear, ambos foram realizados com o auxílio do programa SPSS IBM, versão teste, disponível no site do fabricante.

\section{RESULTADOS E DISCUSSÃO}

O estudo contemplou 44 bairros e 3 conjuntos da RMB, totalizando 440 questionários. No entanto, ressalta-se que esse total não pôde ser usado integralmente na análise da DAP dos entrevistados. Devido à forma de aplicação da pesquisa em que o preenchimento total de alguns questionários não foi completo, os mesmos foram descartados antes da construção da curva de regressão. Porém, para a caracterização dos consumidores de água tratada da RMB, utilizaram-se os 440 questionários aplicados. 
Em relação ao sexo da população amostrada, $52 \%$ são do sexo feminino e $48 \%$ são do masculino. O perfil etário dos entrevistados demonstrou que cerca de $70 \%$ dos usuários têm idade entre 21 a 50 anos, estando no auge das suas atividades laborais, e apenas $2,1 \%$ são maiores que 70 anos. No que concerne ao nível de escolaridade, a maioria dos entrevistados possuem ensino médio completo e/ou ensino técnico (55\%), $22 \%$ possuem ensino superior e apenas $1 \%$ têm algum tipo de pós-graduação.

Em relação à renda média familiar, aproximadamente metade da população amostrada ganha entre um e três salários mínimos e 18,7\% ganha de três a cinco salários. A participação das classes extremas na pesquisa, isto é, com renda inferior a um salário mínimo ou superior a sete salários, atingiu a mesma porcentagem de entrevistados, cerca de $9 \%$ do total. O valor do salário mínimo considerado no estudo foi $\mathrm{R} \$ 724,00$.

A média do número de habitantes nas residências da RMB encontrada na pesquisa foi de 4,23 habitantes por domicílio, com desvio padrão de 2,51 e valores mínimos e máximos de 1 e 12 habitantes, respectivamente. Enquanto que o número de pessoas que trabalham por residência é de 2,29, em média (desvio padrão de 1,28).

A medição do consumo da água tratada dá-se por hidrômetro em $40 \%$ das residências que participaram da pesquisa. Esse porcentual pode ser maior, pois 5,5\% dos entrevistados afirmaram não saber o valor pago na fatura de água, pois o valor encontra-se incluso no condomínio ou aluguel. Assim, não há como afirmar se há ou não o micromedidor. Porém, 50\% dos entrevistados possuem tarifa fixa, ou seja, pagam um valor mensal pré-definido. O valor cobrado é estimado segundo as características da residência, como pontos de utilização de água, número de cômodos e tipo de construção.

Além disso, destaca-se que 4,3\% dos entrevistados não pagam pela água tratada, representando as perdas de água aparente da concessionária. Dentre os motivos da não cobrança, além de alguns possuírem conexões ilegais, muitos afirmaram que a cobrança simplesmente ainda não chegou às suas residências.

Em relação à qualidade e regularidade da água pública, destaca-se que mais $38 \%$ dos entrevistados consideram a qualidade da água ruim, e aproximadamente $26 \%$ sofrem frequentemente com a falta de água, o que indica falhas no sistema de abastecimento, bem como necessidade de revitalização do mesmo. Apesar de 42,6\% dos entrevistados considerarem a regularidade do fornecimento de água boa, ressalta-se que esse resultado é consequência direta da presença de caixas d'água em parte das residências, que evitam a percepção das variações de vazão de água.

Quando perguntado sobre a forma de purificação utilizada para o consumo da água, 65,2\% dos consumidores responderam que compram água mineral, portanto, não utilizam a água fornecida pela concessionária para beber. Dentre os motivos alegados, destaca-se a impossibilidade de consumo devido ao alto teor de ferro presente na água, fato que foi relatado por múltiplos usuários. Assim, induz-se que a população estaria disposta a pagar mais pela água, caso a mesma tivesse melhor qualidade, pois seria reduzido o valor gasto com água mineral.

O método mais utilizado para purificar a água é a filtração, escolhido por aproximadamente $23 \%$ dos entrevistados. Além desse, também são utilizados os métodos de coar $(2 \%)$, ferver (2\%) ou adicionar hipoclorito $(3,6 \%)$ e 3,9\% dos usuários consomem a água tratada sem fazer uso de nenhum método de purificação.

No que diz respeito à destinação final do efluente produzido, 30,7\% possuem fossa. De acordo com Leão et al (2007), o uso da fossa séptica é uma alternativa à população que não possui esgotamento sanitário, possibilitando a redução dos riscos de contaminação dos mananciais e da disseminação de enfermidades causadas pelos esgotos a céu aberto.

Dentre os que não possuem fossa, 29,1\% dos consumidores têm suas residências conectadas à rede de esgoto e aproximadamente $30 \%$ dos usuários lançam seu esgoto diretamente na sarjeta, 
que é carregado juntamente com a drenagem pluvial. Este tipo de disposição do efluente, aumenta os riscos durante os períodos de cheias na região e, consequentemente, a disseminação de doenças.

O alto índice encontrado de coleta de esgoto $(29,1 \%)$ pode ser resultado da falta de informação da população no que diz respeito ao seu destino final que na RMB é de $15 \%$ sobre o total produzido. Sendo assim, é provável que nem todos os entrevistados que afirmaram ter a residência conectada ao sistema de coleta realmente a tenham.

A fim de mensurar a percepção ambiental dos entrevistados, indagou-se sobre a existência de relação entre pagamento pelo uso do recurso ambiental e desperdício do mesmo. Aproximadamente $74 \%$ da população consideraram que a cobrança para a utilização do recurso resulta na diminuição do seu desperdício. Somente $26 \%$ dos entrevistados avaliaram não haver relação entre os dois aspectos, porém, muitos deles acreditam ser necessária a conscientização dos cidadãos, a fim de que seja alcançado um consumo racional.

Após a construção do perfil socioeconômico da população usuária de água tratada na RMB, foi realizada a análise da DAP de cada entrevistado. Da população entrevistada, $81,1 \%$ afirmaram estar dispostos a pagar pelo recurso "água". Assim, apenas 18,9\% não estão dispostos a pagar um valor adicional na sua conta de água pelo recurso.

Dentre os motivos alegados, destaca-se que $40 \%$ dos cidadãos consideram que suas contas de água já são demasiado caras e que o aprimoramento do sistema de fornecimento de água é de reponsabilidade do governo. Além disso, $21 \%$ dos entrevistados não acreditam em melhoria do sistema, porque não confiam na administração do governo.

Assim, têm receio de pagar mais pela utilização da água sem que haja desenvolvimento e ampliação dos sistemas de abastecimento de água e coleta de esgoto. Destaca-se também o percentual de $11 \%$ que retrata os indivíduos que não possuem condições financeiras de pagar um adicional pelo recurso. O restante $(29 \%)$ está satisfeito com o serviço de abastecimento de água da COSANPA.

A fim de explicar a varável dependente (DAP dos usuários), foi realizada uma série de tentativas de ajuste do modelo gerado. Devido ao baixo nível de explicação alcançado e com o intuito de aprimorar o ajuste dos dados, excluíram-se as residências cujo preço não reflete o consumo da família e consideraram-se somente duas variáveis com potencial de explicação: "valor da fatura" e "renda média".

Dessa forma, retiraram-se da análise os questionários referentes à tarifa fixa, pois o valor pago não reflete o valor real de consumo,uma vez que não há medição do volume consumido. Mesmo que a família consuma um volume superior ou inferior ao valor da taxa, sempre pagará o mesmo preço na conta de água. Além disso, foram eliminados da análise os questionários que não estavam completamente preenchidos.

Após a exclusão dos questionários, totalizou-se 119 questionários válidos que puderam ser utilizados para a explicação da DAP dos entrevistados. A tabela 2 descreve o comportamento das variáveis incluídas no modelo.

Tabela 2. Estatística descritiva das variáveis.

\begin{tabular}{lcccc}
\hline Estatística descritiva & Média & $\begin{array}{c}\text { Desvio } \\
\text { Padräo }\end{array}$ & Mínimo & Máximo \\
\hline Disposição a pagar & 2,08 & 0,74 & 1,40 & 5,00 \\
Renda média & 2583,06 & 1457,09 & 724,00 & 5792,33 \\
Valor da Fatura & 52,78 & 39,46 & 10,00 & 290,00 \\
\hline
\end{tabular}


O modelo de regressão gerado, com o intuito de explicar as oscilações na DAP, apresentou $\mathrm{R}$ de 0,155 e $\mathrm{R}^{2}$ de ajustado de 0,14 . Desse modo, afirma-se que aproximadamente $14 \%$ da variação da DAP estão sendo explicadas pelos parâmetros selecionados para o modelo.

O baixo nível de explicação do modelo pode ter sido consequência da falta de continuidade temporal dos dados obtidos. Como a pesquisa foi realizada durante um curto período de tempo, ela contém informações referentes a um mesmo momento. Dessa forma, o estudo baseia-se em dados obtidos a partir de um corte transversal no tempo, sem que fosse realizada uma continuidade das informações. A tabela 3 apresenta os resultados obtidos pelo modelo.

Tabela 3. Modelo de Regressão Linear

\begin{tabular}{cccc}
\hline $\begin{array}{c}\text { Variáveis } \\
\text { explicativas }\end{array}$ & Coeficientes & Estatística t & $\begin{array}{c}\text { Nivel de } \\
\text { significância }\end{array}$ \\
\hline Constante & 1,728440 & 13,252658 & $5,68241 \mathrm{E}-25$ \\
Renda média & $8,27475 \mathrm{E}-05$ & 2,011889619 & 0,046548959 \\
Valor da Fatura & 0,005395 & 3,552425 & 0,000553 \\
\hline
\end{tabular}

Através do modelo, estimou-se a DAP média individual em $\mathrm{R} \$ 2,22$ por $\mathrm{m}^{3}$ consumido, obtendo-se um aumento de 0,82 sobre o mínimo cobrado atualmente pela COSANPA. Assim, de acordo com o modelo aplicado, observa-se que o preço mínimo do $\mathrm{m}^{3}$ da água tratada pode ser elevado de $\mathrm{R} \$ 1,40$ para até aproximadamente $\mathrm{R} \$ 2,22$. A DAP máxima encontrada pelo modelo foi de $\mathrm{R} \$ 3,77$ e a mínima $\mathrm{R} \$ 1,84$.

Com base nas disposições a pagar mínima, média e máxima, no consumo médio por faixa de consumo obtido com a COSANPA e no número de economias existentes na área estudada, foi possível determinar três cenários de aplicação para as novas tarifas. Primeiramente, adotou-se a variação de cada DAP estimada nas outras taxas de consumo da COSANPA, como está disposto na tabela 4.

Tabela 4. Modificações das tarifas a partir da DAP por água em $\mathrm{R} \$ / \mathrm{m}^{3}$

\begin{tabular}{cccc}
\hline Valor atual & DAP mínima & DAP média & DAP máxima \\
\hline 1,4 & 1,84 & 2,22 & 3,77 \\
2 & 2,44 & 2,82 & 4,37 \\
2,68 & 3,12 & 3,5 & 5,05 \\
3,02 & 3,46 & 3,84 & 5,39 \\
4,18 & 4,62 & 5 & 6,55 \\
5,43 & 5,87 & 6,25 & 7,80 \\
\hline
\end{tabular}

A partir da aplicação das tarifas modificadas, encontrou-se os possíveis valores extras a serem arrecadados em cada faixa de consumo, representados no gráfico 1. 


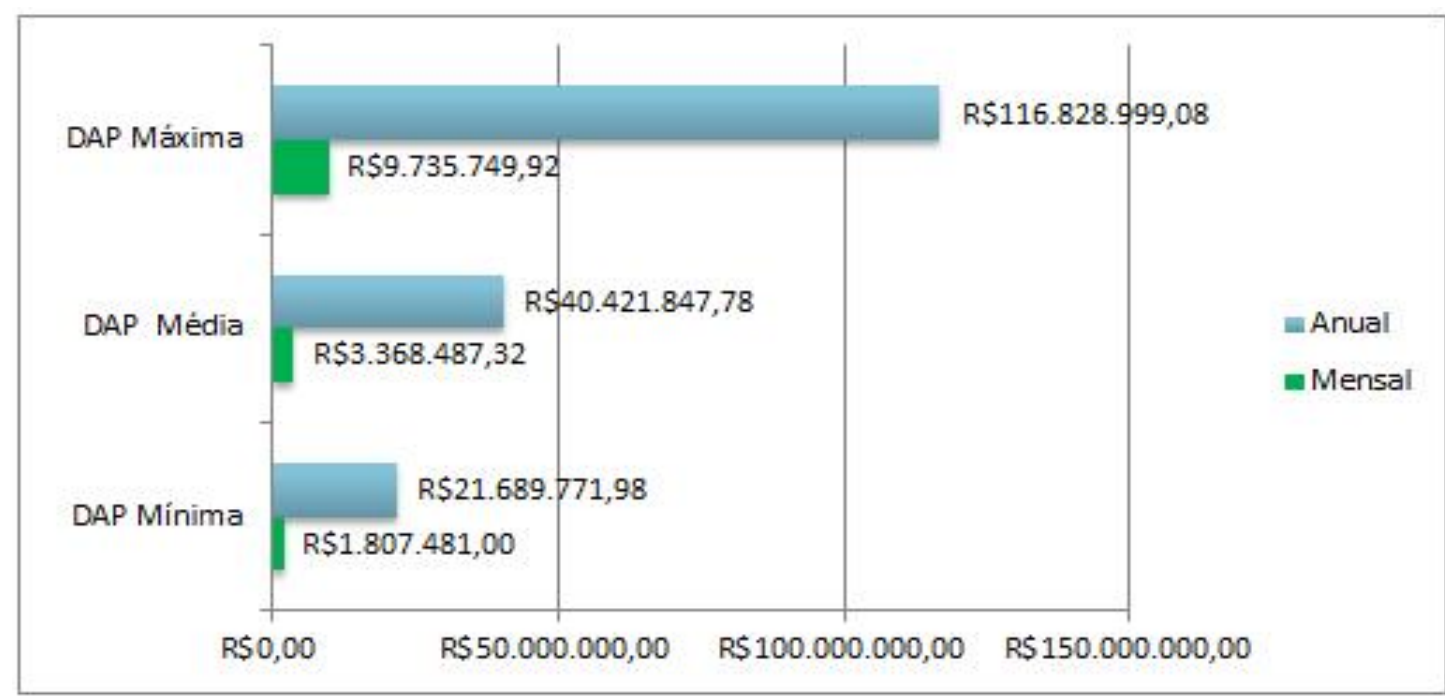

Figura 2. Receitas mensais e anuais geradas por meio da cobrança pela água na RMB

Portanto, somente com a adoção da DAP mínima já seria possível arrecadar mais de R \$21 milhões ao longo de um ano, possibilitando maiores investimentos no sistema de abastecimento de água da RMB, bem como na expansão do sistema de coleta de esgoto domiciliar.

\section{CONCLUSÕES}

Se aplicado o modelo, os valores arrecadados deverão ser aplicados na realização de investimentos nos aspectos operacionais do sistema de abastecimento de água, a fim de garantir menor índice de perdas e evitar a perda de qualidade da água, de forma a não prejudicar o consumidor final. Também deverão ser feitos investimentos no sistema de coleta e tratamento de esgoto, para que o mesmo seja ampliado e garanta o tratamento do efluente antes de seu lançamento no corpo hídrico.

Além da mudança no preço do $\mathrm{m}^{3}$ da água, sugere-se a implantação de micromedidores em todas as residências, de forma a efetivamente medir e controlar o volume de água utilizada por cada economia. Desse modo, será cobrado somente o valor real gasto pela residência.

A quantidade de entrevistados, cujas disposições a pagar foram utilizadas para explicar a DAP, está abaixo do número mínimo necessário para que a mesma seja atribuída à toda população. Além disso, a pesquisa considerou somente a DAP de usuários que possuem hidrômetro, desconsiderando os usuários de taxa fixa e os que não sabiam o preço pago pelo Destaca-se aqui a importância de mais estudos sobre esse tema, que possam ultrapassar a categoria residencial de consumo e reunir dados das outras categorias da COSANPA, como também das residências que possuem poços ou outra forma de abastecimento de água. Assim, será possível o envolvimento de maior número de participantes, bem como a possibilidade de expansão da DAP estimada para toda a população da RMB.

\section{REFERÊNCIAS}

CARRERA-FERNANDEZ, J.; MENEZES, W. A avaliação contingente e a estimativa da função de demanda por água potável. Revista Econômica do Nordeste, Fortaleza, v. 31, n. 1, p. 8-34, janmar. 2000. 
COSANPA. Unidades de negócios. Disponível em:

http://www.cosanpa.pa.gov.br/index.php/unidades-de-negocios. Acesso em 04/04/2014 (a)

COSANPA. Taxas cobradas. Disponível em: http://www.cosanpa.pa.gov.br/index.php/taxas. Acesso em: 02/04/2014. Acesso em: 02/04/2014 (b).

COUCERO, S.R.M.; HAMADA, N. Os Instrumentos da Politica Nacional de Recursos Hídricos na Região Norte do Brasil. Oecologia Australis, 15, 4: 762-774, 2011.

HARTMANN, P. A cobrança pelo uso da água como instrumento econômico na política ambiental: estudo comparativo e avaliação econômica dos modelos de cobrança pelo uso da água bruta propostos e implementados no Brasil - Porto Alegre: AEBA, 2010.

LEÃO, N.; ALENCAR, C.; VERÍSSIMO, C.A. Belém Sustentável 2007. Belém: Instituto do Homem e Meio Ambiente da Amazônia, 2008, p. 73-83. Disponível em:

http://www.ciflorestas.com.br/arquivos/doc_belem_2007_32185.pdf. Acesso em: 03/09/2014.

MOTTA, R. Economia Ambiental. Rio de Janeiro: FGV, 2006. 228p.

PEREIRA, J.A.R. et al. Sistema de Abastecimento de água da Região Metropolitana de Belém. Síntese do Plano Diretor. 2006. Disponível em:

http://www.ananindeua.pa.gov.br/public/arquivos/planodiretor/PDSAA_GPHS_Sintese.pdf. Acesso em: 29/09/2014.

SILVA, N.N. Amostragem probabilística. ${ }^{a}$ ed. São Paulo: EDUSP; 2001SNIS - Sistema Nacional de Informações de Saneamento. 2012. Série histórica. Disponível em: http://www.cidades.gov.br/serieHistorica/. Acesso em: 20/08/2014. 